\title{
THE EFFECT OF SILANE COUPLING AGENTS ON RADIATA PINE FIBRE FOR USE IN THERMOPLASTIC MATRIX COMPOSITES
}

\author{
K. Pickering ${ }^{1 *}$, A.Abdalla ${ }^{2}$, C. Ji, ${ }^{3}$ A.G. McDonald ${ }^{4}$ and R. A. Franich ${ }^{5}$ \\ 1,2 Department of Materials and Process Engineering, University of Waikato \\ Private Bag 3105, Hamilton \\ 3,4,5 Manufacturing, Forest Research, Private Bag 3020, Rotorua, New Zealand.
}

\begin{abstract}
Gamma aminopropyltriethoxysilane (GS) and dichlorodiethylsilane (DCS) were employed for surface modification of radiata pine (Pinus radiata) wood fibre. Levels of fibre moisture were carefully controlled to optimise chemical and hydrogen bonding with these silane coupling agents. The effect of pre-treatment using $2 \%$ sodium hydroxide, shown to be effective in assisting silane coupling for other natural fibres [1], was also investigated. X-ray Photoelectron Spectroscopy (XPS) and Nuclear Magnetic Resonance (NMR) were used to characterise modification of the wood fibre. Concentrations of up to $3.2 \mathrm{wt} \%$ Si were obtained on the fibre surface due to silane coupling, however, pre-treatment was found to dramatically reduce this value. NMR provided evidence that coupling had occurred between the fibre and DCS by a reaction producing ether linkages between the hydroxyl groups on the wood fibre and silane. Pre-treatment and treatment were found to have an insignificant effect on fibre strength. Composite sheets were
\end{abstract}


produced by blending fibre (5, 10 and 20wt\%) with polyethylene followed by extrusion. An increase in strength was obtained at fibre contents of $5 \mathrm{wt} \%$ for all treatments compared to composites with untreated fibre. This is believed to be mainly due to increased compatibility of the fibre surface to polyethylene. However, there was no such improvement obtained at higher fibre contents. Evidence suggests that the production of voids is limiting composite strength.

Keywords: A.Wood; A. Thermoplastic resin; D. Surface analysis; E. Surface treatment

\section{INTRODUCTION}

New Zealand radiata pine fibre possesses physical and mechanical properties that makes it suitable for reinforcing plastics [2]. Compared to conventional reinforcing fibres, such as glass or carbon, wood fibre has a number of benefits, including low density and biodegradability. In New Zealand, radiata pine fibres are readily available from pulping operations for paper production and from production of fibre for board manufacture. Kraft pulping, a type of chemical pulping process, produces fibres which are nearly pure cellulose [3]. Wood fibre is also produced using thermomechanical pulping (TMP) for lower grade paper and also fibre board manufacture for which higher temperatures would be used, and as a result higher amounts of lignin remain on the fibre surface [4]. Similarly for all composite materials, the mechanical properties of wood fibre reinforced plastic composites, depend not only on the fibre properties, but also on the level of adhesion between the fibres and the matrix material: the fibre/matrix interface has to be sufficiently strong for the composite to obtain reinforcement from the fibres. For wood fibre/thermoplastic composites this sets a 
challenge. Here, as for other natural fibre/thermoplastic matrix combinations, the incompatibility of the hydrophilic cellulose fibre and the hydrophobic thermoplastic matrix can actually lead to a reduction in the strength of the composite material as the volume fraction of fibre increases, despite the fibre being the stronger component [5]. Thus, although economical and environmental advantages can be achieved, application of thermoplastic matrix composites is dramatically limited due to the inability to transfer the mechanical properties of the fibre into these materials. In addition, strong fibre-fibre interaction resulting from intermolecular hydrogen bonding limits the dispersion of the fibre in the matrix [6]. Therefore, it is sensible to modify the surface of the wood fibre in order to improve ease of adhesion with and dispersion within the matrix in order to realise the great potential of wood fibre/ thermoplastic matrix composites.

Cellulose fibres contain many hydroxyl groups and readily interact with water molecules by hydrogen bonding. In contrast to glass fibres, where water adsorption only occurs at the surface, cellulose fibres can interact with water throughout their bulk. The quantity of sorbed water depends on the:

- relative humidity of the surrounding atmosphere

- purity of the cellulose

- degree of crystallinity; all $\mathrm{OH}$ groups in the amorphous phase are accessible to polar solutions unlike crystalline phases where only the surfaces are available for water sorption [7].

Sorbed water is considered to decrease the strength of wood fibre/thermoplastic composites [8] due to increasing the incompatibility of the constituents. 
Alternatively, however, the lignocellulose hydroxyl groups could be used to react with compounds to reduce the hydrophylicity of the fibres and therefore increase their compatibility with thermoplastic matrices. Considering different composite systems, one of the most successful and cost effective treatments includes the use of silane-based coupling agents for improving the adhesion between glass fibres and polymer matrices [9]. These chemicals are hydrophylic compounds with different groups appended to silicon, such that one end will interact with hydrophylic compounds and the other end can react with hydrophobic groups. Therefore hydrophylic and hydrophobic materials can be coupled together with the silane coupling agent acting as a bridge between them. Although this type of treatment is well established with glass fibre, its effect on wood fibre has not been extensively studied [6]. Attempts to use silane to improve bonding in wood/polyolefin composites date back to 1983 [10]. The literature has expanded since [11-17], such that researchers have achieved modest improvements in composite strength. However, the strength achieved lies well below that which might be expected using a "rule of mixtures" [18] and so it might be considered that there is scope for improvement. Few studies assess the bonding mechanisms involved with their systems and even less take account of the quantity of silane coupled to the fibre to allow for improved subsequent bonding. Although it is accepted that uptake of silane is very dependent on a number of factors [6] including hydrolysis time, organo-functionality of silane, temperature and $\mathrm{pH}$, however, there are no systematic studies that look to optimise the amount taken up by fibres and assess the effect on composite properties. A single study [1] was found that had measured the amount of silane up-take before incorporating cellulose fibres into a composite. This study was based on henequen fibres, for which a maximum silane adsorption value of approximately $0.37 \mathrm{mg} / \mathrm{g}$ of fibre was achieved using infra-red analysis. Unfortunately, the XPS analysis described does not include the percentage of the surface coupled with silane and the silane was not shown to be chemically bonded to the fibre surface. The treatment, however, brought about modest 
improvements of strength similar to the literature for wood fibre described above. The same study demonstrates the sensivity of adsorption of silane on concentration and hydrolysis time. It also demonstrates the use of sodium hydroxide solution for increasing adsorption of silane. This effect was considered to be due to the removal of lignin and other alkali soluble compounds from the fibre, increasing the number of reactive sites on the fibre.

The current study aims to focus on optimisation of silane up-take using a controlled hydrolysis process in order to optimise composite strength.

\section{EXPERIMENTAL}

\section{Materials}

High temperature thermomechanical Pulp (TMP) wood fibre was supplied by Forest Research, New Zealand, Rotorua, procured from radiata pine (top log chips). Scanning electron micrographs of this fibre are given in Figure 1. The wood fibre was completely dried prior to treatment. Gamma-aminopropyltriethoxysilane $\left(\left(\mathrm{H}_{2} \mathrm{NCH}_{2} \mathrm{CH}_{2} \mathrm{CH}_{2}\right)-\mathrm{Si}\right.$ $\left(\mathrm{OCH}_{2} \mathrm{CH}_{3}\right)_{3}$ designated GS) and dichlorodiethylsilane $\left(\left(\mathrm{CH}_{3} \mathrm{CH}_{2}\right)_{2}-\mathrm{Si}_{-} \mathrm{Cl}_{2}\right.$ designated DCS) coupling agents were supplied by Sigma Chemical Co., St Louis, USA and Aldrich Chemical Co., Milwaukee, USA, respectively. Polyethylene powder (MD1030) was obtained from Clariant (New Zealand) Ltd, Auckland, New Zealand. 


\section{Pre-treatment}

Approximately half of the wood fibre was treated with aqueous sodium hydroxide (2wt\%). After immersion for about two hours, the wood fibre was rinsed using distilled water until it had attained a pH of 7.

\section{Fibre Treatment}

Subsequent to drying and pre-treatment, fibre was left exposed to air until it attained an equilibrium moisture content of $10 \mathrm{wt} \%$. The amount of water bound within wood fibre has been shown to be critically important for hydrolysis of silane [6]. Insufficient water has the potential to lead to an incomplete monolayer on the fibre surface. However, an excess of water can lead to the hydrolysed silane coupling agent reacting with itself to produce a polymerised silane layer that rests on the top of the fibre but is prevented from reacting with the fibre due to the excess water. This layer can easily be removed. It is noted that when silane is applied by immersing wood fibre in a bath of silane solution with excess water, only low contents of silane are observed in the final treated fibre, with higher amounts achieved where dry blending is utilised [1].

For glass fibres, silane treatment is usually applied to fibres either by totally immersing them in an aqueous solution for two to three hour or by dry blending where the silane is applied using a solvent [19]. Generally for long fibres, immersion in an aqueous solution is recommended, although the suitability of this approach for wood fibres has not been previously ascertained. In this work, the immersion method was adopted. Treatment with silane was carried out at a silane concentration of $0.01 \% \mathrm{w} / \mathrm{w}$ of the moisture content of the fibre ( $10 \%$ of the fibre weight), shown elsewhere to be an optimum amount for henequen fibre [1]. A solvent was used in preference to water to encourage hydrolysis to take place with the water on the surface of the fibre rather than within the carrier. The carrier solvent 
used was acetone containing acetic acid (acetone:acetic acid volume ratio of 19:1) to promote hydrolysis [9]. Acetone was used to promote swelling of the fibre and so increase the fibre surface area exposed to treatment. The amount of carrier used was just sufficient to make the wood fibre wet to allow hydrolysis of silane to take place with the bound water. It is believed that any additional water would increase the possibility of hydrolysis away from the fibre. After immersion, the fibre was left for over half an hour to dry in air and then oven dried at $60^{\circ} \mathrm{C}$ for 24 hours. The fibre was then thoroughly rinsed using pure acetone and then dried again After immersion, the fibre was left for over half an hour to dry in air and then oven dried at for 24 hours.

\section{XPS analysis}

XPS spectra were recorded on a Kratos 800 ESCA/SAM spectrometer (University of Auckland) using A1 Ka (1486.6 eV) radiation and a sample chamber pressure of the order of $10^{-10}$ torr. The samples were analysed for the carbon $1 \mathrm{~s}$, silicon $2 \mathrm{p}$, and oxygen 1 s peaks. An area of approximately $20 \mathrm{~mm}^{2}$ of sample was analysed.

\section{${ }^{29}$ Si NMR analysis}

29Si NMR spectra were acquired on a Bruker Avance 200 equipped with a $7 \mathrm{~mm}$ MAS accessory. Samples were packed in $7 \mathrm{~mm} \mathrm{ZrO}$ rotors and spun at $5 \mathrm{kHz}$ at $25^{\circ} \mathrm{C}$. A single pulse sequence using a relaxation delay of $20 \mathrm{~s}$ with a $30^{\circ}$ pulse width $\left(90^{\circ}=15 \mathrm{~ms}\right)$. Exponential line broadening of $40 \mathrm{~Hz}$ was applied prior to Fourier transform.

\section{Single fibre tensile testing}

Single fibre tensile testing was carried out to assess the strength of the available radiata pine fibres and the effect of pre-treatment and treatment. Testing was carried out based on ASTM 
D3379-75 with an Instron 4204 tensile testing machine and a $10 \mathrm{~N}$ load cell, using 20 samples for each treatment regime. The gauge length was set to $1 \mathrm{~mm}$. Diameter measurements were obtained using an optical microscope with a calibrated eye-piece.

\section{Composite Production}

The treated fibres were blended with polyethylene powder using a food processor to give fibre contents of 5,10 , and $20 \mathrm{wt} \%$. These mixtures were then dried in the oven at $60^{\circ} \mathrm{C}$ for 24 hours, then transferred to a twin screw extruder and converted to composite sheets of approximately $1 \mathrm{~mm}$ thick. These were then pelletised and re-extruded for maximum homogeneity. Samples were prepared for tensile testing according to ISO/R527-1966 (Plastics, Determination of Tensile Properties).

\section{Electron Microscopy}

The degree of fibre dispersion and interfacial bonding was assessed by scanning electron microscopy (SEM) studies of freeze cut surfaces.

\section{RESULT AND DISCUSSION}

XPS spectra results for untreated fibres are shown in Fig.2 for comparison with those for treated fibres (with and without sodium hydroxide (S) pre-treatment) as shown in Figs. 3 and 4 for treatment with GS and DCS respectively. Elemental breakdown for all samples is summarised in Table 1. The analysed silicon mass concentration was $2.3 \%, 3.2 \%, 2.2 \%$, and $0 \%$ for fibres treated with GS, DCS, DCS $+S$, and GS+S respectively. The main features that can be observed in the spectra for the untreated fibre are associated with carbon $\mathrm{C}_{1 \text { s }}$ and $\mathrm{O}_{1 \text { s }}$ photoelectrons. For the treated fibres, the surface chemistry can be seen to have changed for all samples except for that pre-treated and treated with GS. For all other samples there is 
clear evidence from the observation of the $\mathrm{Si}_{2 \mathrm{p}}$ peak at $105 \mathrm{eV}$ (Figs. 3a and 4) indicating a reaction having taken place between the hydroxyl groups on the fibre and silane. Conclusive evidence for the incorporation of silane onto the wood fibre after DCS treatment was provided by solid state ${ }^{29} \mathrm{Si}$ NMR through a signal at $-56.8 \mathrm{ppm}$ chemical shift (Fig. 5 ). This is interpreted as a $\mathrm{Si}$ atom with two R groups (ethyl) and two Si-O bonds with an alkyl group substituted on the oxygen [20]. However, since the ${ }^{29} \mathrm{Si}$ signal is broad, it is likely that mixtures of diethylsilicon-oxygen bonded species are present depending on the sites of attachment. The peak, at $-58 \mathrm{ppm}$, is indicative of silicon bound to oxygen attached to a saturated carbon (such as carbohydrate) [20], while the shoulder at $-30 \mathrm{ppm}$ would indicate silicon bound to oxygen carrying an unsaturated or aromatic carbon (such as lignin) [20].

The reaction mechanisms for DCS could be described as follows. Initially, hydrolysis of silane to silanol occurs with the water bound in the wood fibre as described [9]:

$$
\left(\mathrm{CH}_{3} \mathrm{CH}_{2}\right)_{2} \mathrm{SiCl}_{2}+2 \mathrm{H}_{2} \mathrm{O} \longrightarrow\left(\mathrm{CH}_{3} \mathrm{CH}_{2}\right)_{2} \mathrm{Si}(\mathrm{OH})_{2}+2 \mathrm{HCl}
$$

After hydrolysis, the molecules of silanol can react with hydroxyl groups on the fibre surface forming ether bonds as shown in Figure 6 and producing ethyl groups at the wood fibre surface increasing compatibility with polyethylene.

For GS, the amine group would become protonated due to the presence of acetic acid in the carrier. A reaction could occur between silicon atom of the coupling agent and the hydroxyl group on the fibre as shown in Figure 7. XPS results suggest that this has occurred for the sample treated with GS without pre-treatment.

However there is no such evidence for the sample that had undergone pre-treatment. An alternative reaction that could occur is between the protonated group of the coupling and acetic acid to form a solid that would precipitate and deposit onto the fibre as follows: 


\section{$\mathrm{CH}_{3} \mathrm{CO}_{2}{ }^{-} \mathrm{H}_{3} \mathrm{~N}^{+}\left(\mathrm{CH}_{2}\right)_{3} \mathrm{Si}(\mathrm{OX})_{3}+3 \mathrm{H}_{2} \mathrm{O} \longrightarrow \mathrm{CH}_{3} \mathrm{CO}_{2}{ }^{-} \mathrm{H}_{3} \mathrm{~N}^{+}\left(\mathrm{CH}_{2}\right)_{3} \mathrm{Si}(\mathrm{OH})_{3}+3(\mathrm{XOH})$}

where $\mathrm{X}$ could be an ethyl $\left(\mathrm{C}_{2} \mathrm{H}_{5}\right)$ or acetyl $\left(\mathrm{CH}_{3} \mathrm{CO}\right)$ group depending on the extent of the reaction with acetic acid. At $60^{\circ} \mathrm{C}$ the reaction rate would be hoped to be sufficient whilst avoiding decomposition of the solid back to its original constituents, preserving sufficient water for hydrolysis and avoiding degradation of the fibre in the presence of acetic acid. Following on from this reaction, there is the potential for hydrogen bonding between the protonated amine and the hydroxyl groups on the fibres. The latter reaction is more likely to occur in the more alkaline environment of the pre-treated fibres. Evidence for this would be provided by an XPS peak at $400 \mathrm{eV}$. Indeed, there would seem to be a small peak at this binding energy value (Figure 3b) which does not appear without pre-treatment (Figure 3a), however, this is not significant compared to the background noise of the trace and further work would be required to resolve this.

\section{Single Fibre Testing}

A plot obtained from a tensile test of a single wood fibre is shown in Fig. 8. Disregarding the stepped appearance of the plot, which is merely a feature of the analysis software, it appears that the slope of the load/extension curve increases to failure. However, comparison with results for other cellulose fibres suggests that up to about an extension of $0.17 \mathrm{~mm}$ the machine is merely taking up lateral slack obtained when the sample is placed in the grips. After reaching an extension of $0.17 \mathrm{~mm}$ it is believed that the plot is showing the true characteristics of the fibre which are observed to be approximately linear up to failure. Failure was observed to occur within the gauge length in a brittle manner (Fig. 9). The average strengths obtained for untreated fibres and pre-treated fibres as well as that for fibres treated with DCS are given in Table 2. As can be seen from the standard deviation, there was 
a large variation in strength values obtained, as would be expected from natural fibres. To further explore these variations, strength was plotted versus diameter as shown in Fig. 10 for all different treatment regimes tested along with least squares best straight line fits. The fibre strength is consistently shown to decrease as the diameter increases.

In order to define the fibre strength distribution, the fibre data was analysed according to a two parameter Weibull distribution. This distribution is commonly used for synthetic fibres such as carbon with large strength variations [21]. In this type of situation the Weibull equation can be written as:

$$
P_{f(L)}=1-\exp \left[-L\left(\frac{\sigma-\sigma_{u}}{\sigma_{0}}\right)^{W}\right]
$$

where $P_{f(L)}$ is the probability of failure of a fibre of length $L$ at an applied stress $\sigma$, and $\sigma_{0}$ is the characteristic strength of a unit length and is the stress at which the probability of failure of a unit length is $0.632(1-\exp (-1))$. $\sigma \mathrm{u}$ is the lowest value of strength and is often set to 0 for simplification, producing what is commonly known as a two parameter Weibull distribution. The shape parameter or Weibull modulus (w) describes the variability of the strength, a low value of $\mathrm{w}$ indication high variability. The two parameter Weibull distribution expression can be rearranged to produce the following equation:

$$
\ln \ln \left[\frac{1}{1-P_{f(L)}}\right]=w \ln \sigma-w \ln \sigma_{0}+\ln L
$$

By plotting $\ln \ln \left[1 /\left(1-\mathrm{P}_{\mathrm{f}(\mathrm{L})}\right)\right]$ versus $\ln \sigma$ (commonly termed a Weibull plot), a straight line of slope $\mathrm{w}$ is obtained, from which $\sigma_{0}$ can be found from the intercept with the $\mathrm{x}$-axis. 
Weibull plots are shown in Fig. 10 for all different treatment regimes tested. Proximity to the best straight line demonstrates a good fit using this distribution. A summary of the Weibull parameters obtained from Fig.11 is given in Table 3. Weibull modulus values are seen to vary from 2.2 to 2.7. Comparison with values obtained with PAN-based carbon fibre of around 6 [22] demonstrates much greater variability for wood fibre.

A similar trend of characteristic strength with change of treatment (Table 3) is seen as for average strength (Table 2), however, the differences between treatments are small when compared with the data spread. Analysis of variants and t-test analysis were used to analyse for the effect of pre-treatment and treatment with DCS. It was found that pre-treatment and treatment with DCS were shown to have an insignificant effect on the strength of the fibres.

\section{Composite Properties}

The strength of composite materials reinforced with untreated wood fibre is shown in Fig. 12 as well as that for the polyethylene matrix material. Similar to other work $[5,23,8]$, this shows an initial decrease in composite strength as the fibre weight percentage increases from $5 w t \%$ to $10 w t \%$, followed by little change at a fibre content of $20 w t \%$. The initial reduction of strength obtained on addition of untreated wood fibre was expected due to fibre-matrix incompatibility as described previously. For fibre additions of $5 \mathrm{wt} \%$, silane treatment (Fig.13 and Table 4) generally resulted in improvement in strength compared to untreated fibre composites, although not above that of the matrix only value of $13 \mathrm{MPa}$. Other researchers have seen improvements in strength of flax fibres [24] due to treatment, however, in this work the strength of the fibres was not seen to be significantly affected and therefore 
this increase is considered to be due to increased compatibility between the fibre and the matrix.

Similar increases in strength were not reflected at higher fibre contents. Here, there was a similar trend for 3 out of the 4 sample types (GS, DCS, DCS $+S)$. For these samples, surface treatment gave little benefit in strength at $10 \mathrm{wt} \%$ fibre content and at the highest fibre percentages, an actual reduction in strength was observed. One explanation for the general reduction in the strength for the treated wood fibre as the fibre weight percentage increases (10wt\% and 20wt\%) could be related to fibre agglomeration, which, would be more likely at higher fibre contents. Fibre-fibre interaction from hydrogen bonding is considered to be a significant barrier to fibre dispersion [6]. Micrographs of untreated and treated wood fibre composites with different fibre weight percentages are presented in Figure 14. There was a tendency for all the samples to be more plastically deformed by the knife in the lower half of the section due to them warming up during cutting. Generally, improved interfacial bonding is demonstrated for samples with surface treated fibre, particularly at the low fibre weight fraction where the matrix has retained close proximity with the fibre across the entire section. However, wood fibre appears well dispersed through all of the samples and so does not seem to explain the reduction of strength at increased fibre content. An alternative explanation could be the increased occurrence of voids observed at higher fibre contents (see figure 14). These could occur due to moisture or other volatiles given off from the fibre during processing.

Another effect that could be limiting the composite strength is due to the carrier for the coupling agent. Acetone is quite likely to be removing fatty acids and waxes from the fibre surface, which themselves would be relatively compatible with the thermoplastic [25]. 
Future work is aimed at assessing further the overall improvement in compatibility of such treatments and how these might be optimised further.

For GS+S treated samples, the strength was consistently lower at 10 and $20 \mathrm{wt} \%$ fibre. As discussed previously, there was no conclusive evidence of silane coupled to the fibre. However, this seems to be in conflict with the improvement in strength observed at $5 \mathrm{wt} \%$ fibre. Certainly this improvement cannot be explained by coupled silane leading to improved bonding. To understand this trend further, we must examine the effect of just the sodium hydroxide pre-treatment on composite strength as shown in Fig. 14. It can be seen that the strength of the samples pre-treated with sodium hydroxide has increased at the fibre content of $5 \mathrm{wt} \%$ similar to that seen for GS+S. This can be explained by mechanical interlocking [26] assisting bonding as a result of the sodium hydroxide pre-treatment which changes the topography of the fibre [27]. However, this is less effective at higher fibre weight percentages, which again is most likely to be due to the effect of voids as discussed previously.

\section{CONCLUSIONS}

The effect of two silane-based coupling agents, GS and DCS, on radiata pine wood fibre with and without pre-treatment using sodium hydroxide has been investigated using XPS and solid state ${ }^{29}$ Si NMR. XPS results based on the elemental and functional composition of the untreated and treated wood fibres indicate that modification of the fibre surface has occurred for most of the samples. Concentrations of silicon were measured to be 2.3, 3.2, and $2.2 \mathrm{wt} \%$ for GS treated without sodium hydroxide pre-treatment, DCS treated without sodium hydroxide pre-treatment and DCS treated with sodium hydroxide pre-treatment 
respectively. NMR analysis has given firm evidence of a reaction producing ether linkages between the hydroxyl groups on the wood fibre and silane for treatment with DCS. For the fibre that was pre-treated with sodium hydroxide and treated using GS, no conclusive silicon signal was observed. It is suspected that hydrogen bonding could be occurring between the protonated amine and the hydroxyl groups on the fibres, however further work would be needed to resolve this. Surface treatment using silane coupling agents was found to improve the strength of composites containing $5 \mathrm{wt} \%$ fibre, suggesting silane to be assisting in interfacial bonding. Although pre-treatment using sodium hydroxide was seen to reduce the uptake of silane, improvements in strength obtained for pre-treated fibre composites, treated with GS, suggest pre-treatment can enhance coupling through increased mechanical interlocking. Surface treatment gave little benefit in strength at $10 \mathrm{wt} \%$ fibre content, and at the highest fibre content, an actual reduction in strength was observed. It is believed that the production of voids at higher fibre weight percentages mask the advantages of interfacial bonding obtained with $5 \mathrm{wt} \%$ fibre.

\section{ACKNOWLEDGEMENTS}

We would like to acknowledge the following people at Forest Research, Rotorua, New Zealand, for their assistance for this work: Jeremy Warnes for logistical support, Stefan Hill for running NMR spectra and Brendan Lee and Ross Anderson for assistance with extrusion. We would also like to thank Helen Turner at the University of Waikato for assistance with

SEM images and Bryony James, Research Centre for Surface and Materials Science, Auckland, for her support with the XPS analysis. 


\section{REFERENCES:}

1. Valadez-Gonzalez A, Cervantes-Uc J M, Olayo R and Herrera-Franco P J, "Chemical Modification of Henequen Fibers with an Organosilane Coupling Agent”, Composites: Part B: Engineering 1999;30:321-331.

2. Miller N A, Stirling C D and Langford V S M, "Pinus Radiata Fibre/Thermoplastic Composite Materials”, Proc. of the Second Pacific Rim Bio-Based Composite Symposium, Vancouver, Canada 1994:47-54.

3. R.T. Woodhams, G. Thomas and D.K. Rodgers, "Wood Fibers as Reinforcing Fillers for Polyolefins”, Polymer Engineering and Science, 1984, 24, 15, pp1166-1171.

4. N.A. Miller, C.D. Stirling and V.S.M. Van Tilburg, "Effects of Fibre Treatment on Fibre/Matrix Interfacial Bonding in Pinus Radiata Fibre/Thermoplastic Composites”, Polymers \& Polymer Composites, Vol. 3, No. 2, 117-127, 1995.

5. Lee B J and McDonald A G, "Wood Fibre-Plastic Composite Materials for Injection Moulding”, Proc. $5^{\text {th }}$ Pasific Rim Bio-Based Composite Symposium 2000:664-670.

6. Matuana L M, Balatinecz J J, Park C B and Sodhi R N S, "X-ray Photoelectron Spectroscopy Study of Silane-Treated Newsprint-Fibers”, Wood Science and Technology 1999;33:259-270.

7. Gauthier R, Joly C, Coupas A, Gauthier H, and Escoubes M, "Interfaces in Polyolefin/Cellulosic Fibre Composites: Chemical Coupling, Morphology, Correlation with Adhesion and Aging in Moisture”, Polymer Composites 1998;19:287-300.

8. Beshay A D, Kokta B V and Daneault C, "Use of Wood Fibers in Thermoplastic Composites II: Polyethylene”, Polymer Composites 1985;6(4):261-270.

9. Plueddemann E P, “Silane Coupling Agent in Reinforced Plastics”, Eds. John Wiley \& son, Inc.1970:95-106. 
10. Xanthos M, “Processing Conditions and Coupling Agent Effects in Polypropylene/Wood Flour Composites”, Plastics and Rubber Processing and Applications 1983;3:223-228.

11. Beshay A D, Kokta B V and Daneault C, "Use of Wood Fibers in Thermoplastic Composites II:Polyethylene” Polymer Composites 1985;6(4):261-270.

12. Maldas D, Kokta B V, Raj R G and Daneault C, "Improvement of the mechanical Properties of Sawdust wood fiber-polystyrene Composites by Chemical Treatment”, Polymer 1988;29:1255-1265.

13. Bataille P, Ricard L and Sapieha S, "Effects of Cellulose Fibers in Polypropylene Composites”, Polymer Composites 1989;10(2):103-108 .

14. Raj R G, Kokta B V, Grouleau G and Daneault, “The Influence of Coupling Agents on Mechanical Properties of Composites Containing Cellulosic Fillers”, Polym.-Plast. Technol. Eng 1990;29(4):339-353.

15. Raj R G, Kokta B V, Maldas D and Daneault C, ”Use of Wood Fibres in Thermoplastics. VII. The Effect of Coupling Agents in Polyethylene-Wood Fiber Composites”, J. Appl. Polym. Sci.1989;37:1089-1103.

16. Raj R G and Kokta B V, ”Improving the Mechanical Properties of HDPE-Wood Fiber Composites with Additives/Coupling Agents”, ANTEC, Proceedings $49^{\text {th }}$ Annual Technical Conference Montreal Canada 1991:1883-1885.

17. Maldas D and Kokta B V, "Role of Coupling Agents on the Performance of WoodflourFilled Polypropylene Composites”, Intern. J. Polymeric Mater.1994;27:77-88.

18. Askeland R, "The Science and Engineering of Materials”, $3^{\text {rd }}$ edition 1996, Chapman and Hall: 560 .

19. Ishida H, “A Review of Recent Progress in the Studies of Molecular and Microstructure of Coupling Agents and Their Functioning in Composites, Coatings and Adhesive Joints”, Polymer Composites 1984;Vol. 5:101-123. 
20. Williams E A, "Recent Advances in Silicon-29 NMR Spectroscopy”, Annual Review of NMR Spectroscopy 1983;15:235-289.

21. Weibull W, “A Statistical Distribution of Wide Applicability”, J. Appl. Mech., $1951 ; 18: 293$

22. Pickering K L and Murray T, "Weak Link scaling analysis of high-strength carbon fibre”, Composites, Part A 1999; 30:1017-1021.

23. Sain M M, Kokta B V and Imbert C, "Structure-property relationships of fiber-filled polypropylene composite”, Polym. Plast. Technol. Eng. 1994; 33(1):89-104.

24. Stamboulis A, Baillie CA and Peijs T, "Effect of Environmental Condition On Mechanical and Physical Properties of Flax Fibres”, Composites:Part A 2001;32: 11051115.

25. Ribitsch V and Stana-Kleinscheck, “Characterizing Textile Fiber Surfaces with Streaming Potential Measurements”, Textile Research Journal 1998;68(10), 701-707.

26. Matthews F L and Rawlings R D, “Composite Materials: Engineering and Science”, Eds. Chapman\&Hall 1994:61.

27. George J, Bhagawan S S, and Thomas S, "Improved Interaction in Chemically Modified Pineapple Leaf Fiber Reinforced Polyethylene Composite”, Composite Interfaces 1998;5:201-223. 
Table 1. XPS data results

\begin{tabular}{|l|l|l|l|l|l|l|}
\hline \multirow{2}{*}{} & \multicolumn{3}{|l|}{ Mass Concentration \% } & \multicolumn{3}{l|}{ Binding Energy eV } \\
\cline { 2 - 8 } & O & C & Si & O & C & Si \\
\hline Untreated & 37.9 & 62.1 & - & 536 & 289 & - \\
\hline GS & 31.1 & 66.5 & 2.3 & 537 & 289 & 105 \\
\hline GS + S & 37.9 & 62.1 & - & 536 & 289 & - \\
\hline DCS & 30.3 & 66.4 & 3.2 & 536 & 288 & 105 \\
\hline DCS + S & 35.5 & 62.1 & 2.2 & 536 & 288 & 105 \\
\hline
\end{tabular}

Table 2. Single fibre strengths: average and standard deviation

\begin{tabular}{|l|l|l|}
\hline Treatment & Average Strength/MPa & Standard Deviation/MPa \\
\hline Untreated & 211 & 85 \\
\hline DCS & 215 & 116 \\
\hline S & 231 & 103 \\
\hline
\end{tabular}

Table 3.Weibull parameters

\begin{tabular}{|l|l|l|}
\hline Treatment & $\begin{array}{l}\text { Characteristic } \\
\text { Strength/MPa }\end{array}$ & Weibull Modulus \\
\hline Untreated & 237 & 2.7 \\
\hline DCS & 243 & 2.2 \\
\hline S & 262 & 2.5 \\
\hline
\end{tabular}

Table 4. Average composite strengths for untreated and treated fibres

\begin{tabular}{|l|l|l|l|l|l|l|}
\hline $\begin{array}{l}\text { Fibre Weight } \\
\text { Percentage }\end{array}$ & $\begin{array}{l}\text { Untreated } \\
\mathrm{MPa}\end{array}$ & $\begin{array}{l}\text { GS+S } \\
\mathrm{MPa}\end{array}$ & $\begin{array}{l}\text { GS } \\
\mathrm{MPa}\end{array}$ & $\begin{array}{l}\text { DCS } \\
\mathrm{MPa}\end{array}$ & $\begin{array}{l}\text { DCS+S } \\
\mathrm{MPa}\end{array}$ & $\begin{array}{l}\text { Pre-treated } \\
\mathrm{MPa}\end{array}$ \\
\hline 5 & 10.57 & 11.58 & 12.47 & 11.76 & 12.66 & 11.52 \\
\hline 10 & 8.98 & 4.97 & 9.05 & 9.87 & 9.87 & 9.09 \\
\hline 20 & 8.91 & 7.02 & 7.67 & 8.34 & 8.35 & 8.55 \\
\hline
\end{tabular}



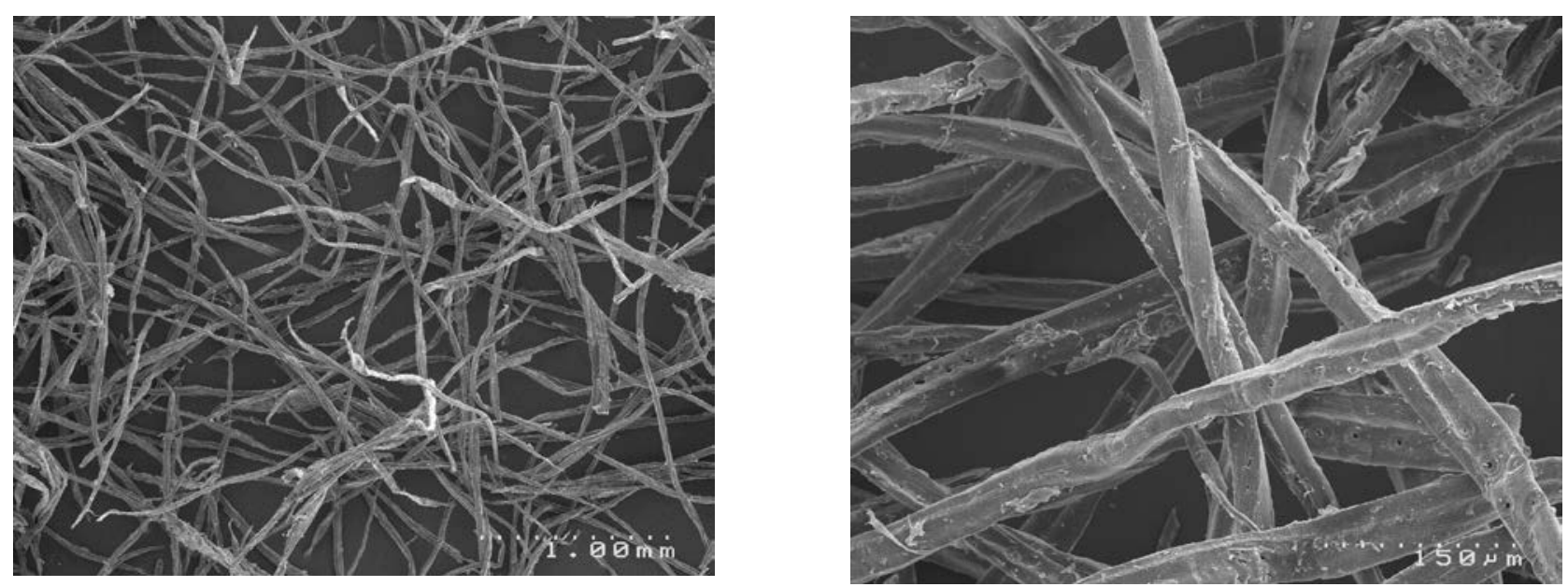

Fig. 1 SEM of high temperature thermomechanical pulp fibre 


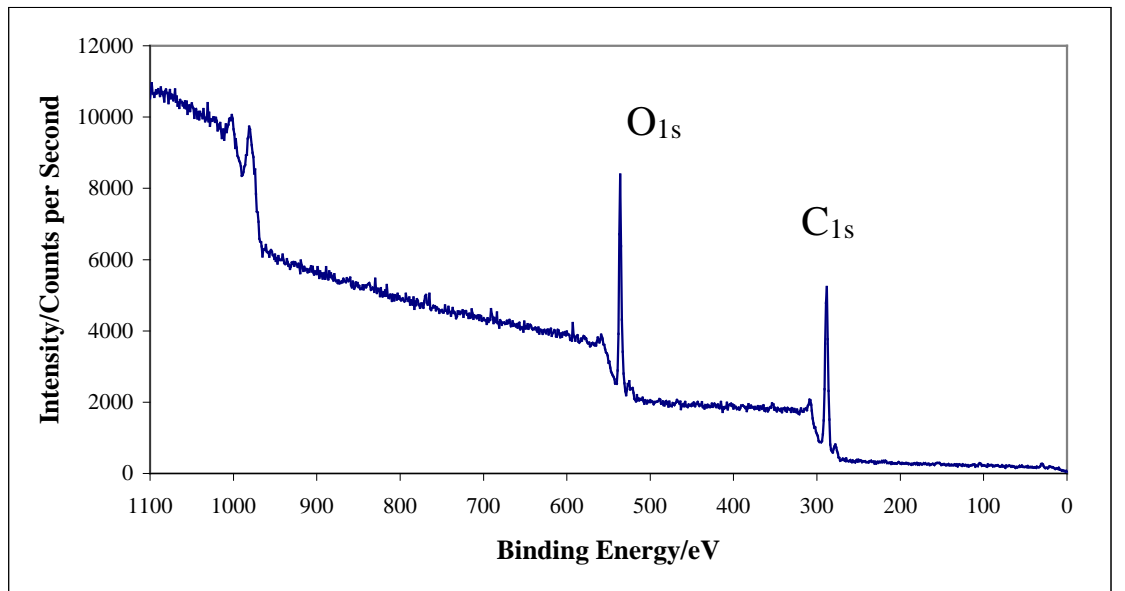

Fig. 2 XPS trace for untreated fibre 
a)

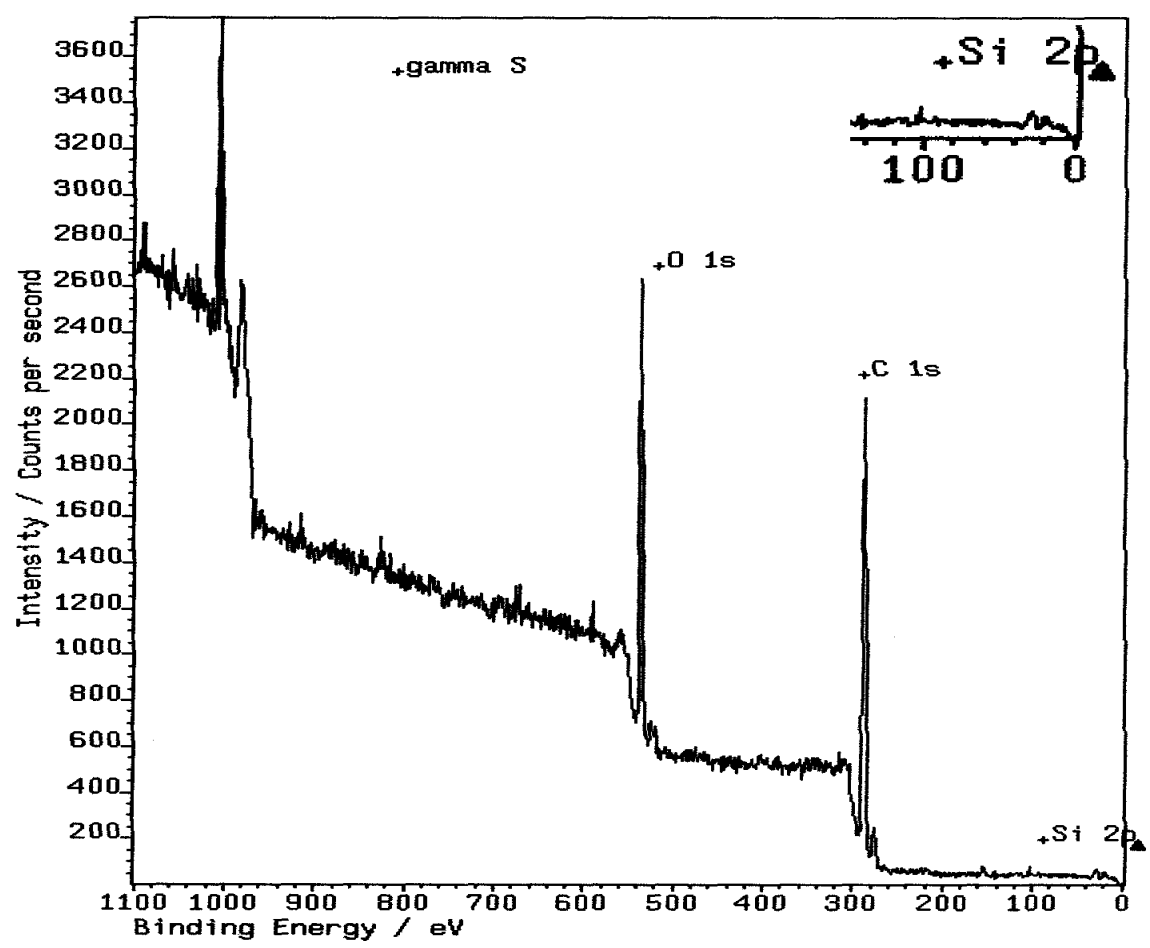

b)

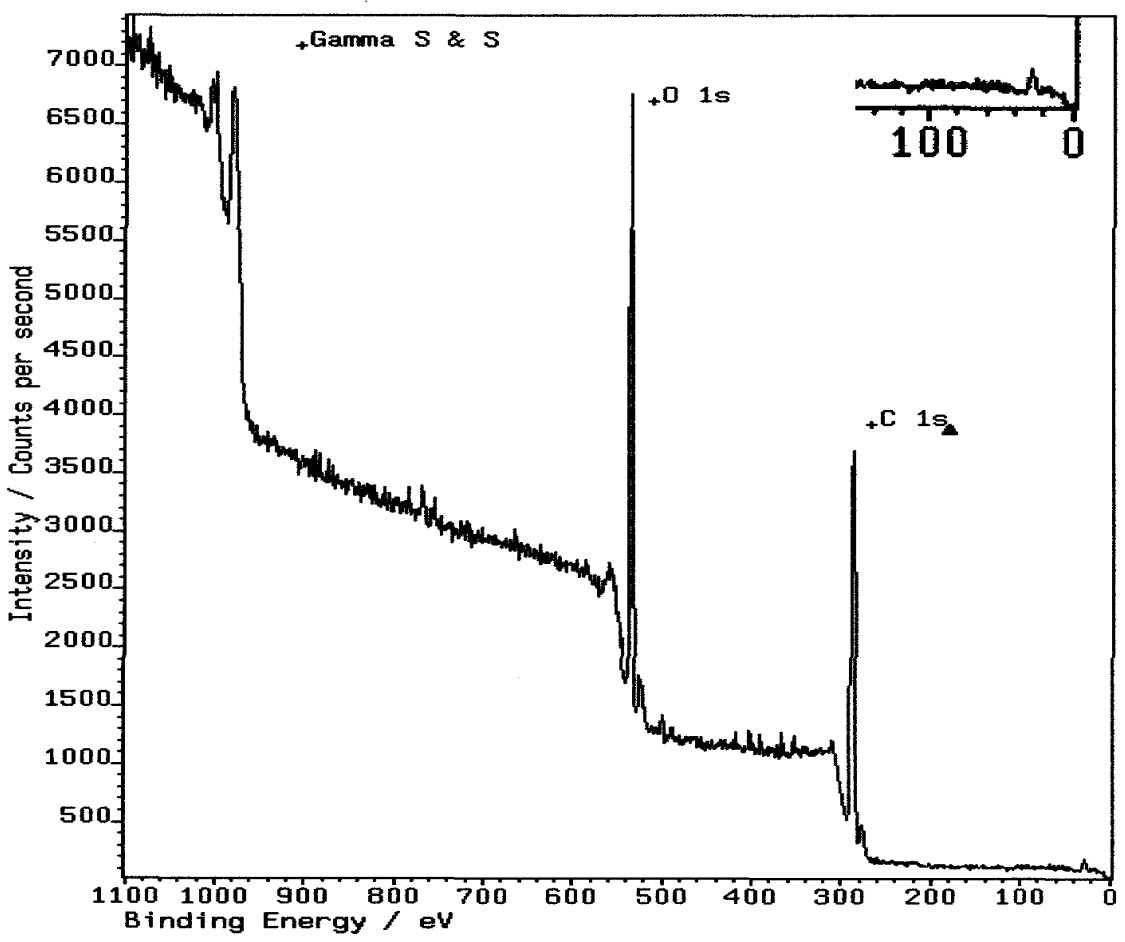

Fig.3 XPS scans for wood fibre treated with GS:

a) without pre-treatment b) with pre-treatment using sodium hydroxide. 
a)

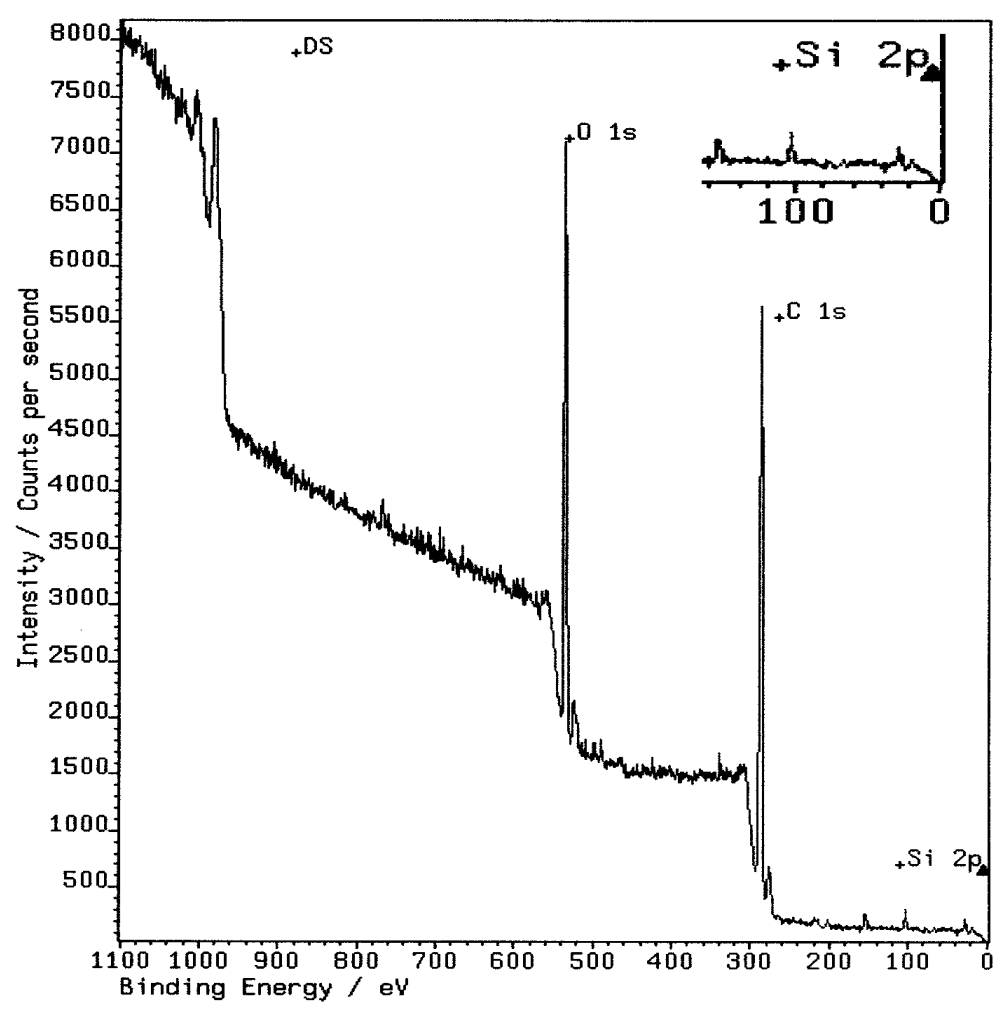

b)

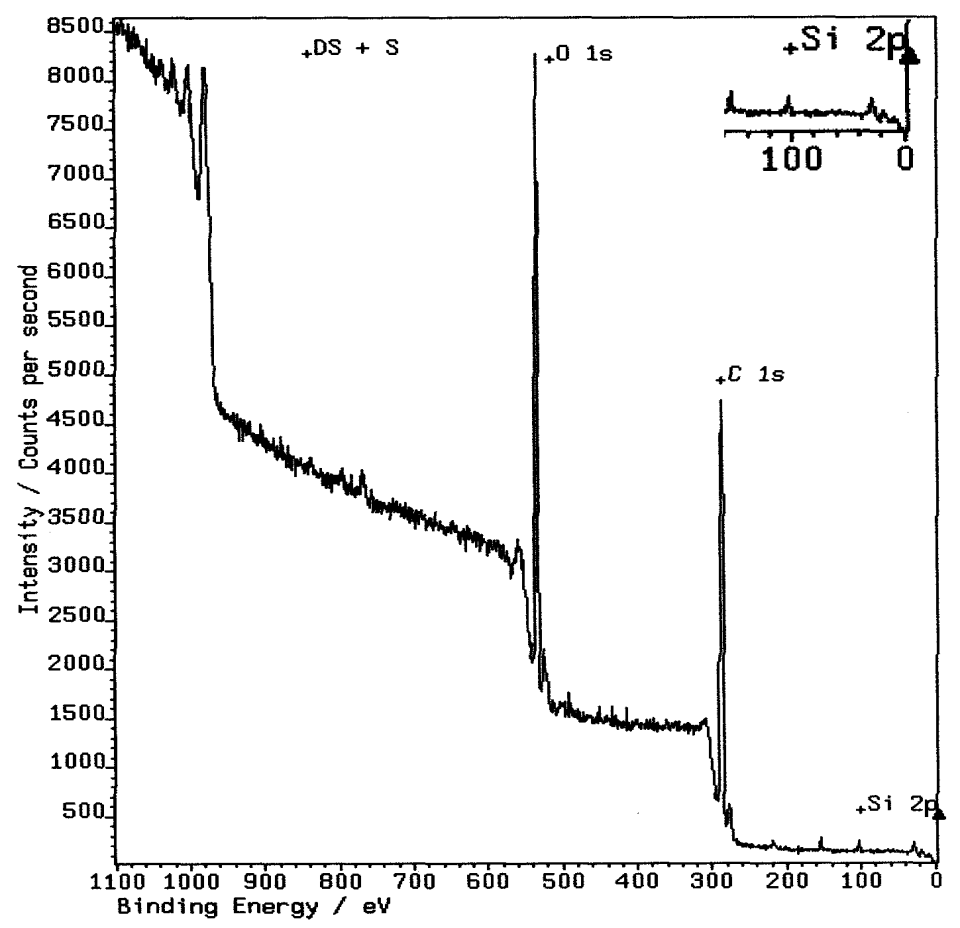

Fig.4 XPS scans for wood fibre treated with DCS:

a) without pre-treatment b) with pre-treatment using sodium hydroxide. 


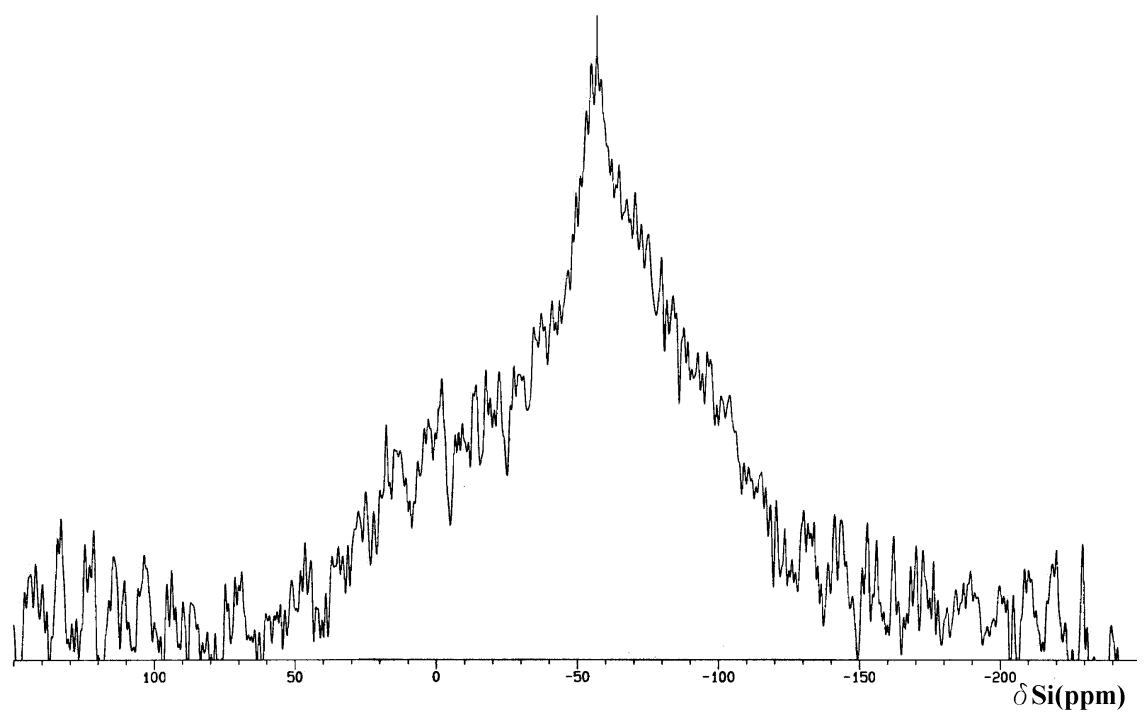

Fig. 5 NMR spectrum for wood fibre treated with DCS without pre-treatment. 


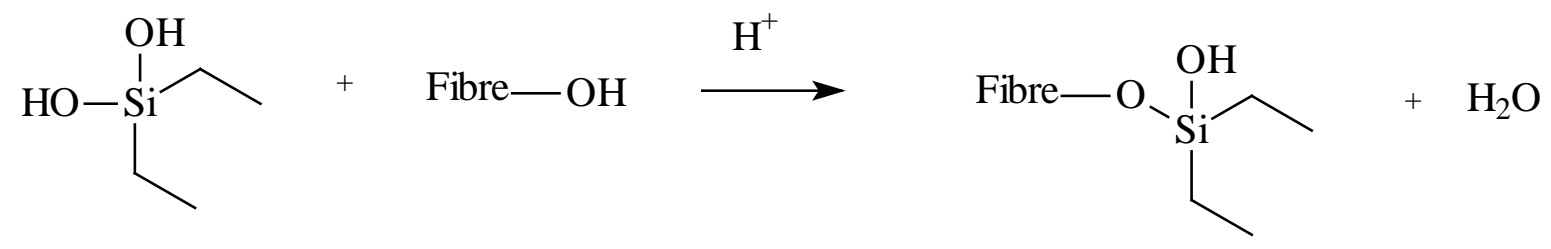

Fig. 6 Silanol reacted with hydroxyl groups on wood fibre 
a)<smiles>CCO[Si](CCCN)(OCC)OCC</smiles><smiles>CCO[Si](CCC[NH3+])(OCC)OCC</smiles><smiles>CCO[Si](CCC[NH3+])(OCC)OCC</smiles><smiles>[3H]CCO[Si](CCC[NH3+])(OCC)OCC</smiles>

b)

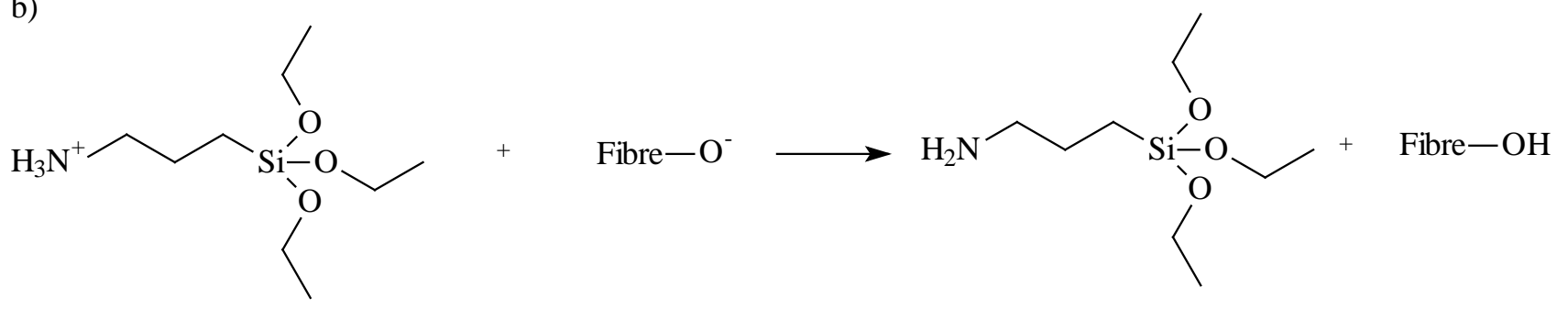

Figure 7: a) Reaction of protonated $\chi$-aminopropyltriethoxysilane with wood fibre.

b) Reaction of protonated $\chi$-aminopropyltriethoxysilane with sodium hydroxide pre-treated fibre. 


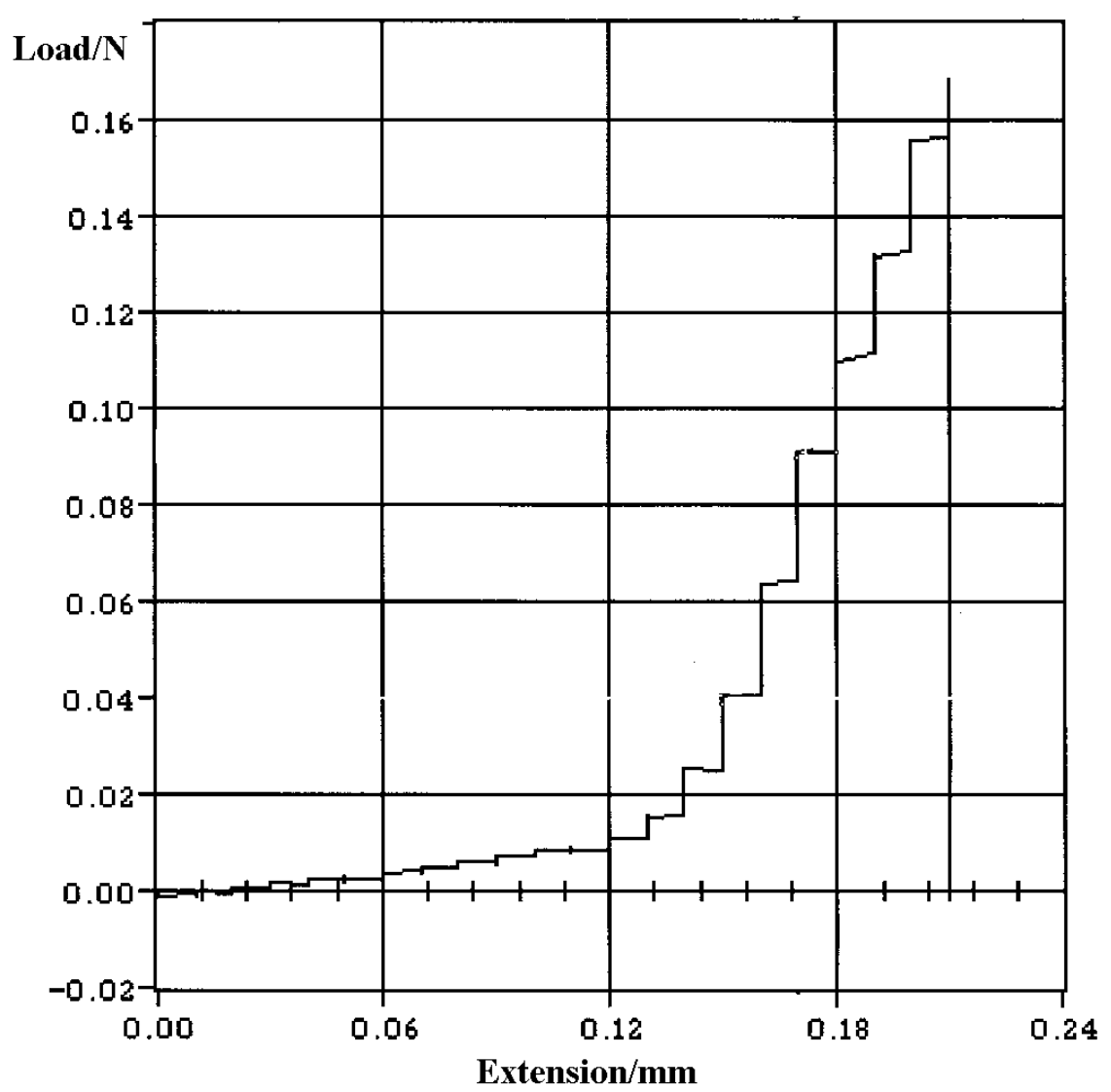

Fig. 8. Single fibre tensile test plot 


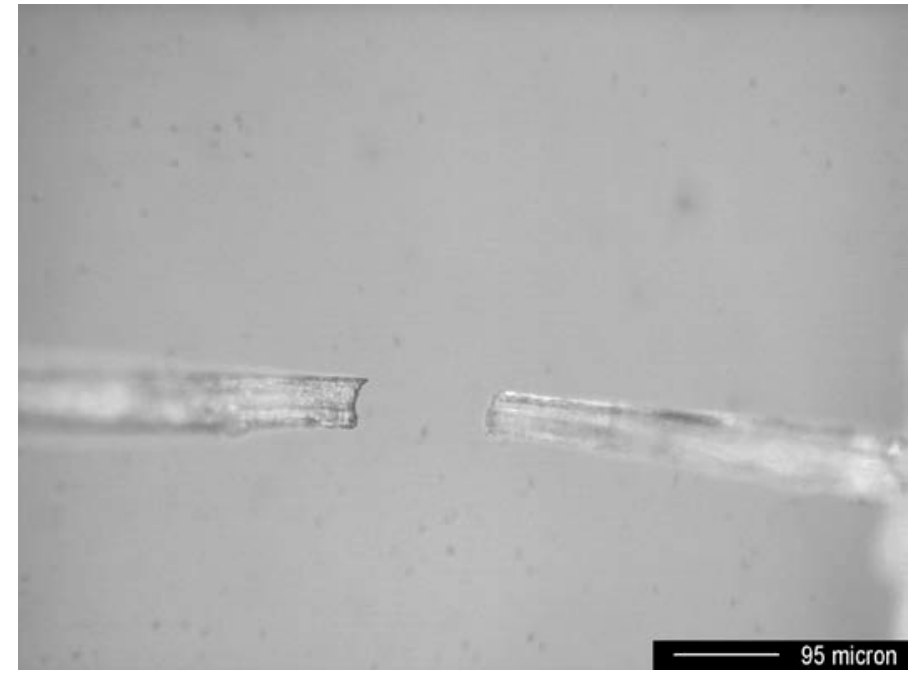

Fig. 9. Single fibre fracture 
a)

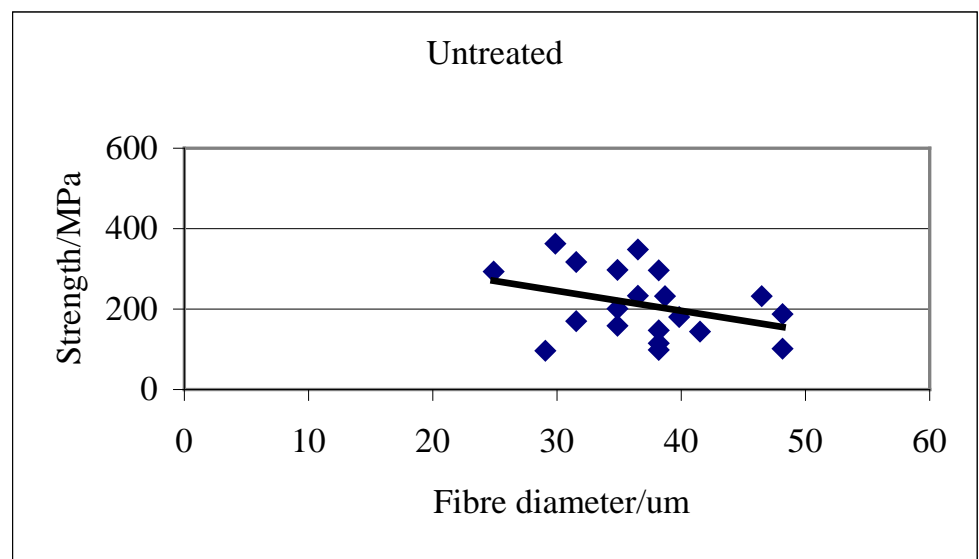

b)

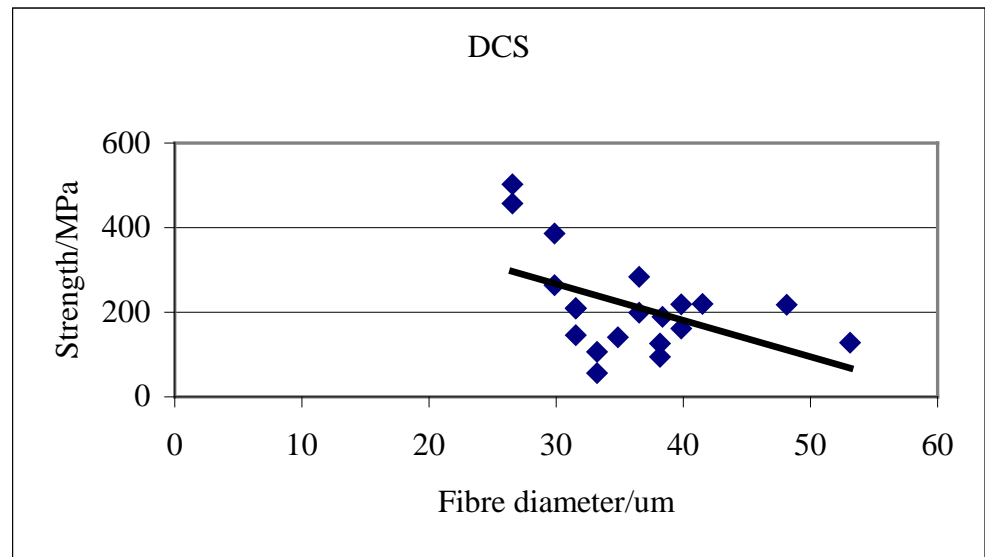

c)

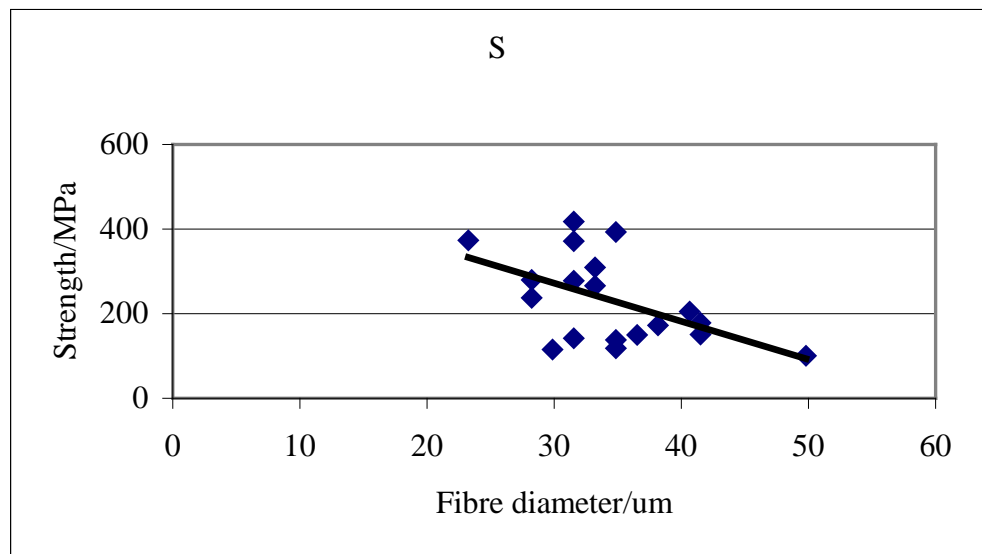

Fig. 10. Strength versus diameter for single fibre tensile tests for a) untreated, b) DCS and c) pre-treated fibres 
a)

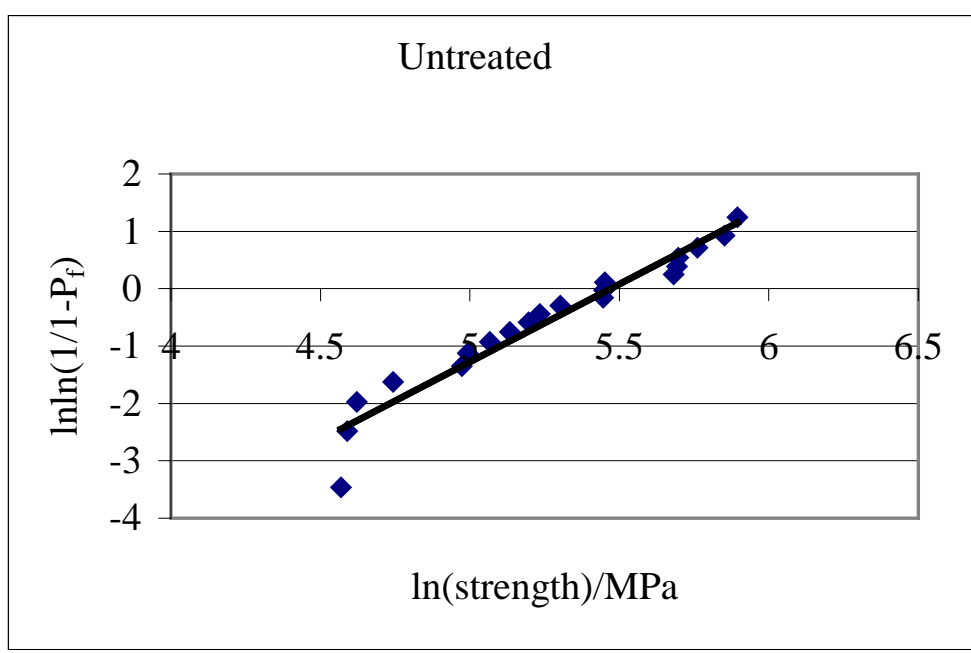

b)

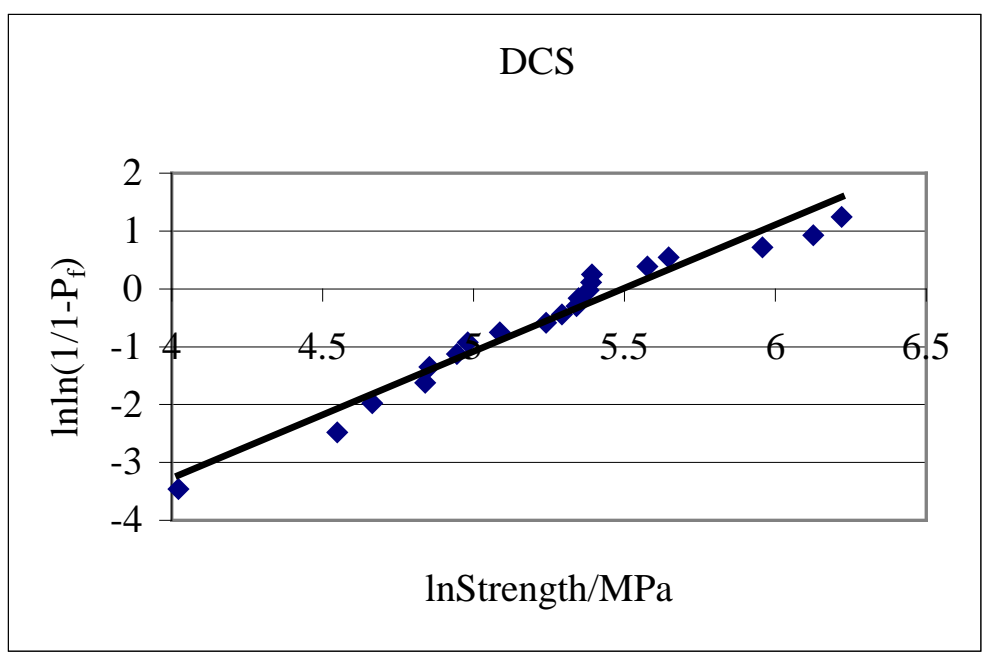

c)

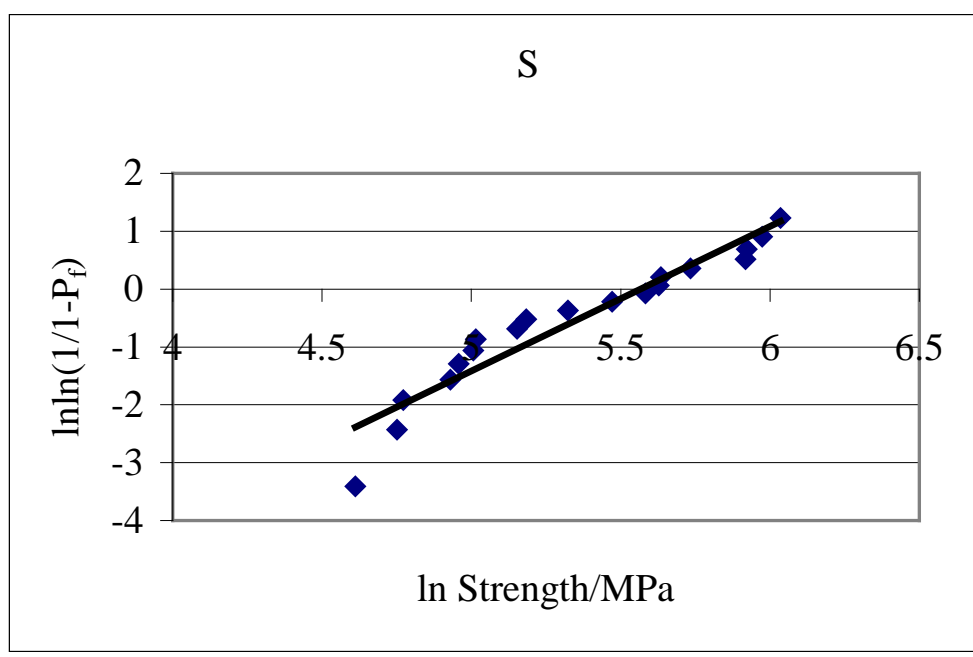

Fig. 11. Single fibre Weibull plots tests for a) untreated, b) DCS and c) pre-treated fibres 


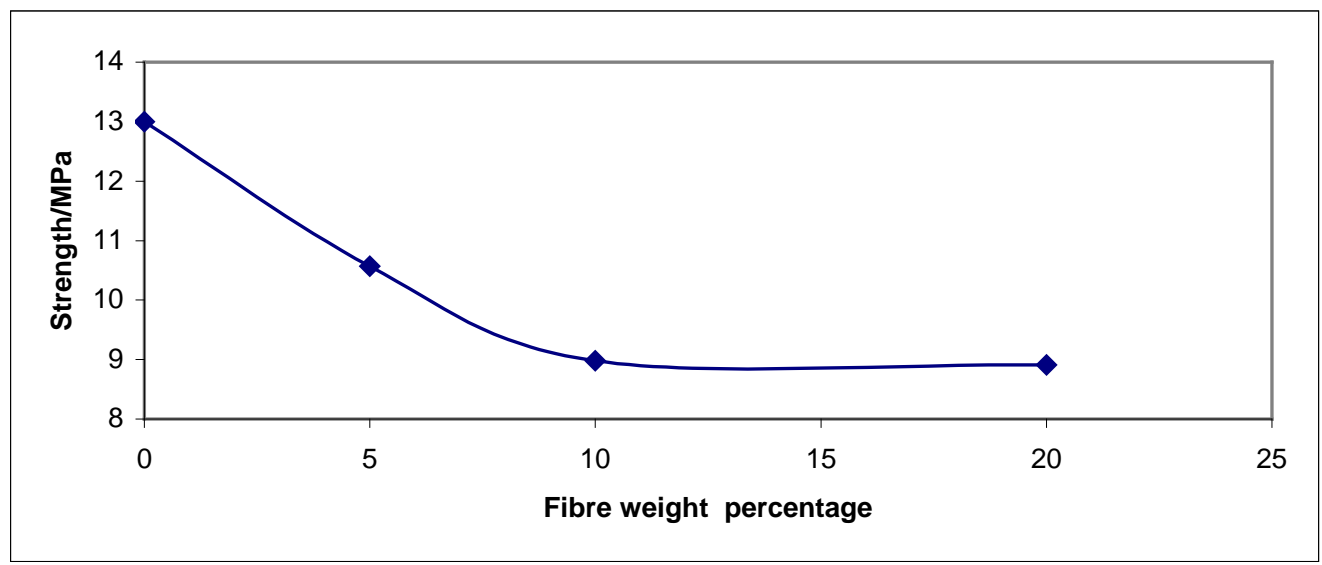

Fig. 12. Composite strength versus fibre weight percentage for untreated wood fibre 
a)

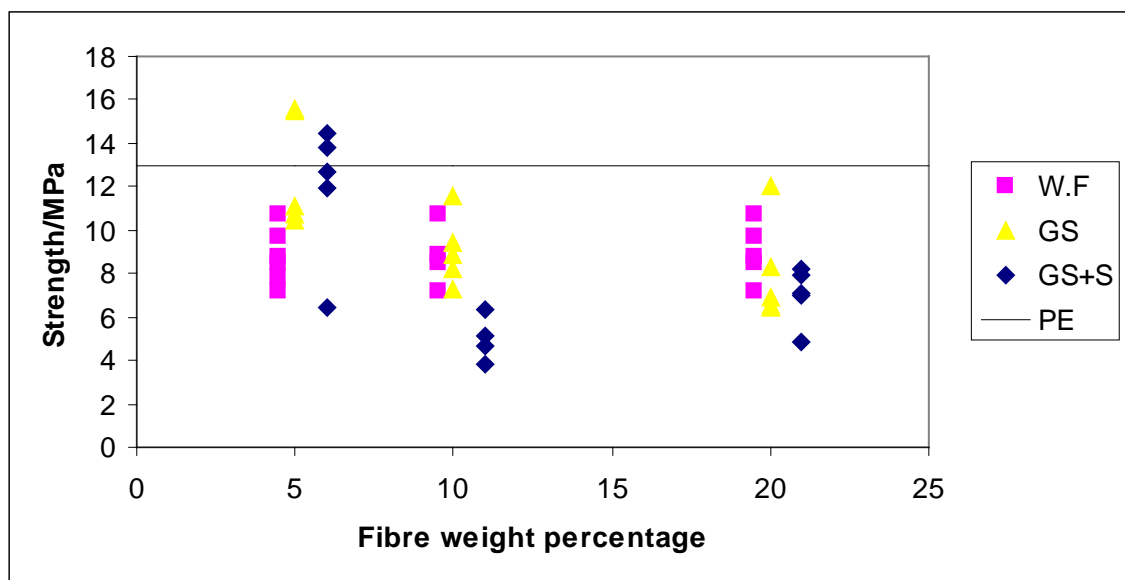

b)

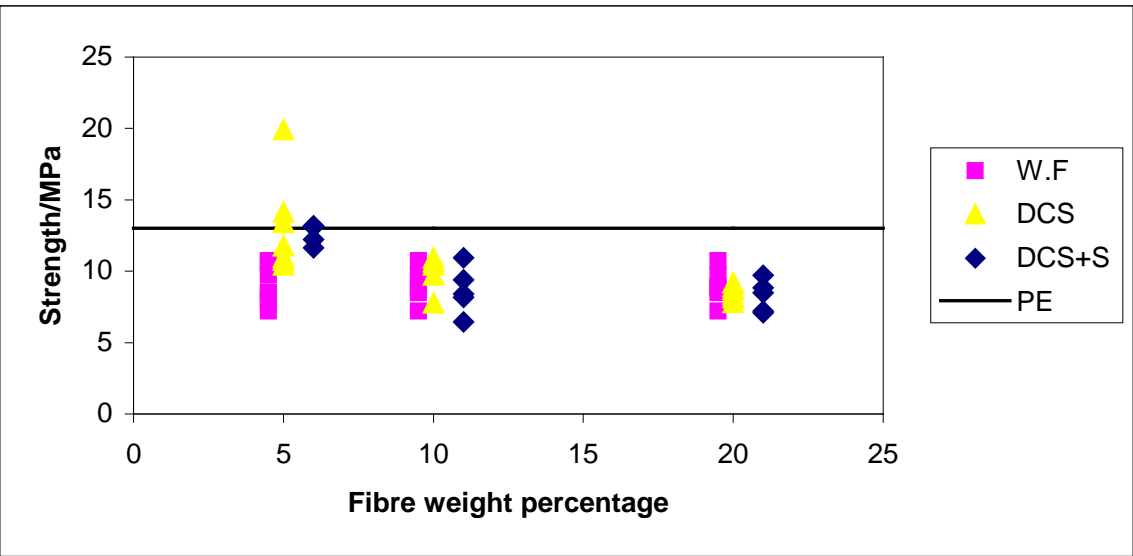

Fig. 13. Comparison of composite strength versus fibre weight percentage for untreated fibre samples compared to samples with a) fibre treated with GS and GS+S, b) fibre treated with DCS and DCS+S. The strength of the polyethylene matrix is shown as a line for comparison. 
a)

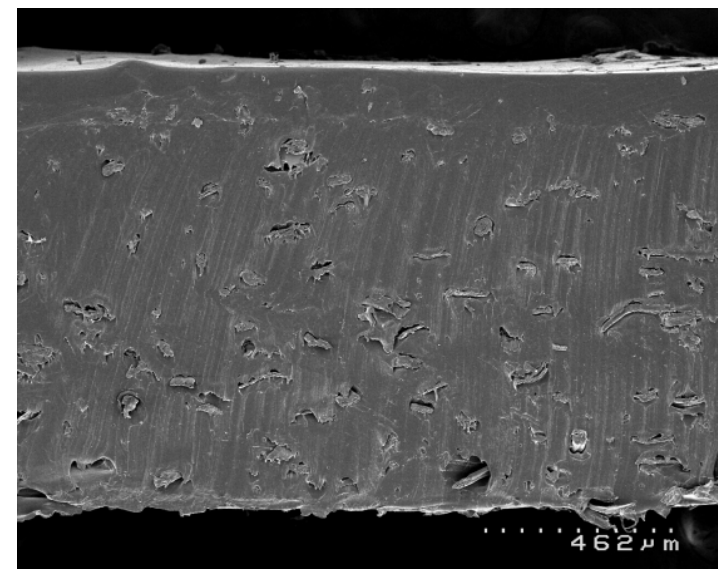

(i) $5 \mathrm{wt} \%$ fibre

b)

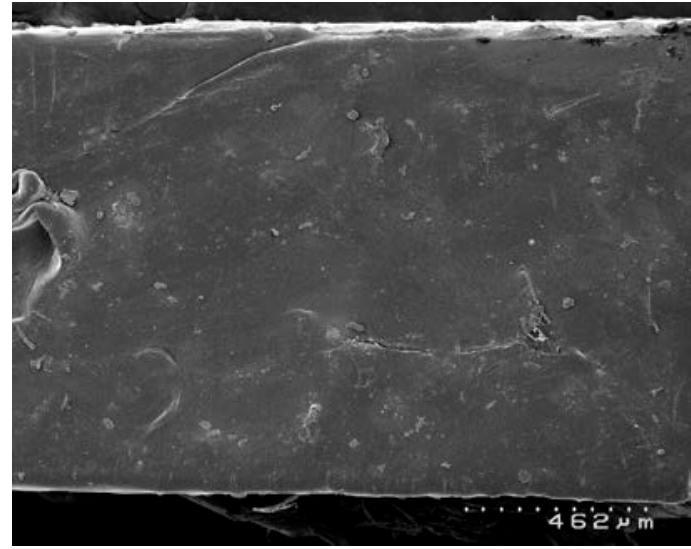

(i) $5 \mathrm{wt} \%$ fibre

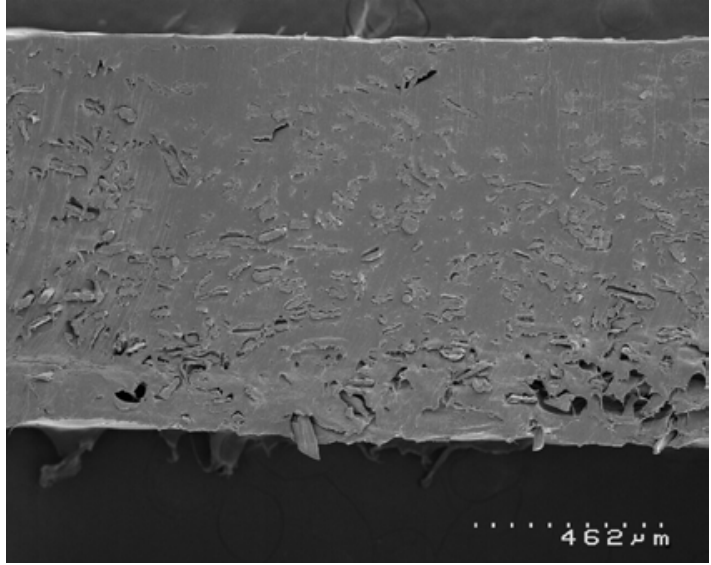

(ii) $20 \mathrm{wt} \%$ fibre

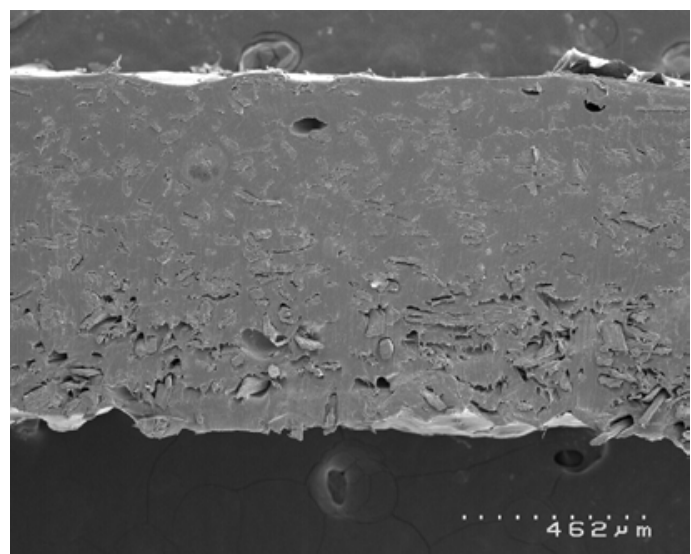

(ii) $20 \mathrm{wt} \%$ fibre

Figure 14: SEM micrographs of composites with a) untreated and b) GS treated fibre. 


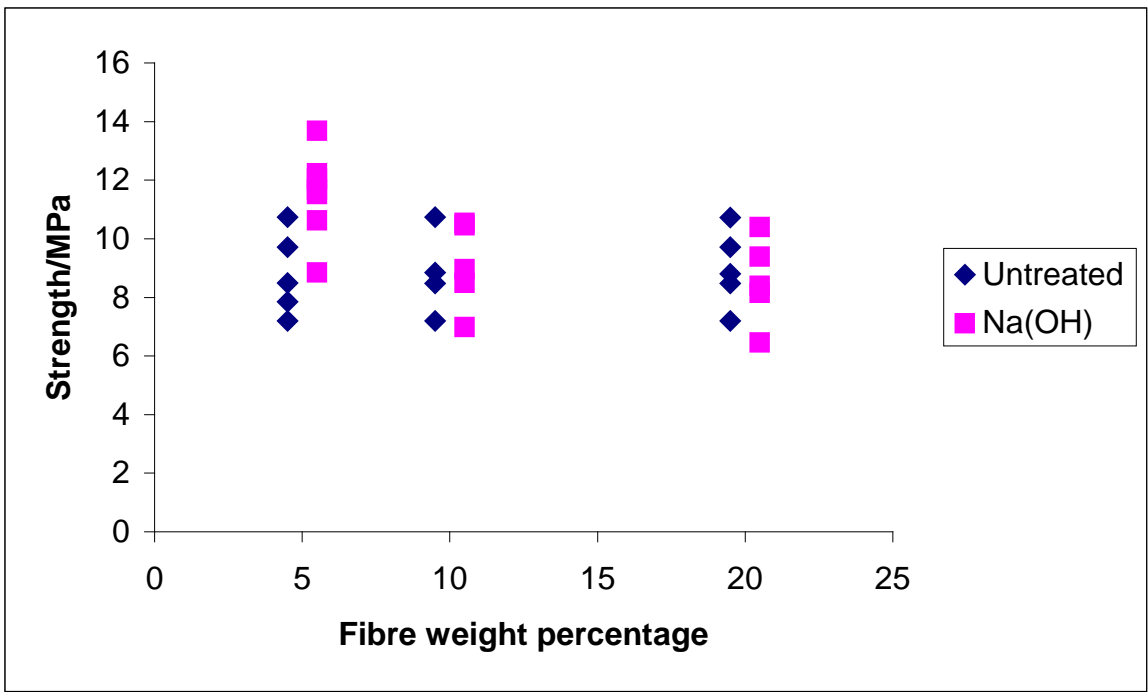

Fig. 15. Composite strength for untreated and pre-treated wood fibre versus fibre weight percentage 